\title{
“NÃO CREIAS TU NISSO, LEITOR AMADO": SOBRE A DATAÇÃO DOS CONTOS DE VÁRIAS HISTÓRIAS
}

Saulo Neiva

(Université Blaise Pascal / Clermont 11)

\section{RESUMO}

Complementos e correções da datação dos contos de Várias histórias, proposta por Galante de Sousa (1955), e desde então transmitida quase fielmente por diferentes fontes.

Palavras-chave: Machado de Assis; Gazeta de Notícias; Várias histórias; conto; datação

Upa! Cá estamos. Custou-lhe, não, leitor amigo? É para que não acredite nas pessoas que vão ao Corcovado, e dizem que ali a impressão da altura é tal, que o homem fica sendo cousa nenhuma. Opinião pânica e falsa, - falsa como Judas e outros diamantes. Não creias tu nisso, leitor amado. Nem Corcovados, nem Himalaias, valem muita cousa ao pé da tua cabeça, que os mede.

$(\text { ASSIS, 1885) })^{1}$

Extraídas do conto "O cônego ou metafísica do estilo", de Machado de Assis, essas poucas linhas foram publicadas no jornal carioca Gazeta de Noticias, no domingo 22 de novembro de 1885 - ou seja, praticamente cinco meses depois do início, no dia 1 de julho, do funcionamento integral da estrada de ferro do Cosme Velho ao Corcovado. Para o então "leitor amigo" da Gazeta, portanto, somente recentemente é que se tornara possível desfrutar da "impressão da altura" do cume do célebre monte. Experiência recentemente realizável mas ainda muito distante da realidade trivial em que ela se transformou, para o "leitor amigo" de hoje. Na época, portanto, a comparação entre a subida à cabeça do cônego e a ascensão do cume do Corcovado era dotada de uma saborosa atualidade que, com o tempo, se atenuou ou até se 
esvaiu. Daí um dos aspectos importantes da pesquisa, que apresentamos neste artigo, consistindo em datar com precisão a publicação desses contos no jornal. Uma datação que é fundamental para, em seguida, confrontarmos o texto publicado pelo autor no jornal com o que, mais tarde, foi publicado em livro.

Naquele domingo de 1885, a satírica história do cônego Matias ocupou integralmente a sétima e a oitava colunas da primeira página e quase um terço da primeira coluna da segunda página da Gazeta. Foi, vale lembrar, um dos 53 contos do autor a terem sido publicados nesse periódico de grande circulação, entre 1882 e 1895. Quase dez anos mais tarde esse relato, numa versão ligeiramente modificada, serviria de fecho à coletânea Várias histórias. Esta obra reuniu dezesseis contos de Machado de Assis, na seguinte ordem: "A cartomante", "Entre santos", "Uns braços", "Um homem célebre", "A desejada das gentes", "A causa secreta”, "Trio em lá menor", "Adão e Eva”, "O enfermeiro", "O diplomático", "Mariana", "Conto de escola", "Um apólogo", "Dona Paula", "Viver!", "O cônego ou metafísica do estilo". Todos esses contos estamparam a primeira página ou o suplemento literário do mesmo periódico, entre 1884, quando o autor publicou Histórias sem data, e 1891, ano do lançamento de Quincas Borba.

Ainda em vida, Machado de Assis veio a lançar três edições do livro. Além da que foi datada de 1896 (apesar de ter começado a circular já em 1895), pela editora Laemmert, foram publicadas as de 1903 e 1904, pela Garnier.

Diversos detalhes textuais - que podem passar despercebidos ou que, de início, podemos até tratar desdenhosamente - separam "O cônego ou metafísica do estilo" publicado na Gazeta da sua versão em livro. O trecho que nos interessa, por exemplo, varia em três momentos: 


\begin{tabular}{|c|c|}
\hline 188 & \\
\hline $\begin{array}{l}\text { Upa! Cá estamos. Custou-lhe, não, } \\
\text { leitor amigo? É para que não acredi- } \\
\text { te nas pessoas que vão ao Corcova- } \\
\text { do, e dizem que ali a impressão da } \\
\text { altura é tal, que o homem fica sen- } \\
\text { do cousa nenhuma. Opinião pânica } \\
\text { e falsa, - falsa como Judas e outros } \\
\text { diamantes. Não creias tu nisso, lei- } \\
\text { tor amado. Nem Corcovados, nem } \\
\text { Himalaias, valem muita cousa ao pé } \\
\text { da tua cabeça, que os mede. }\end{array}$ & $\begin{array}{l}\text { Upa! Cá estamos. Custou-te, não, } \\
\text { leitor amigo? É para que não acre- } \\
\text { dites nas pessoas que vão ao Corco- } \\
\text { vado, e dizem que ali a impressão da } \\
\text { altura é tal, que o homem fica sen- } \\
\text { do cousa nenhuma. Opinião pânica } \\
\text { e falsa, - falsa como Judas e outros } \\
\text { diamantes. Não creias tu nisso, lei- } \\
\text { tor amado. Nem Corcovados, nem } \\
\text { Himalaias valem muita cousa ao pé } \\
\text { da tua cabeça, que os mede. }\end{array}$ \\
\hline
\end{tabular}

Quadro 1: Cotejo de trecho de "0 cônego ou metafísica do estilo"

Essa simples confrontação de um breve trecho, salientando-se as modificações realizadas pelo autor, já basta para abandonarmos a atitude inicial de desatenção ou de desdém: as diferenças entre as duas versões, que considerávamos como meros detalhes sem interesse para a compreensão do texto, se impõem como um conjunto de variações bastante significativas para estudarmos esse mesmo texto, tal qual foi publicado na imprensa e em livro, e para melhor entendermos o horizonte inicial da sua recepção. Variações que justificam plenamente a realização de uma confrontação mais ampla entre essas versões.

Para tanto, pretendemos recorrer ao conceito de "texto em variação", através do qual "estados de textos sucessivos" (HEIDMANN et ADAM, 2010 , p. 157 seg.) podem ser agrupados em um corpus a ser estudado. Não se trata, para nós, de cotejar as diferentes versões, animados pelo objetivo de determinar qual variação deve ser considerada mais "pertinente" (seria a mais recente, por corresponder à última palavra do autor? ou, ao contrário, a mais antiga, por indicar uma escolha mais "autêntica" do seu gênio?...). Não. Em vez disso, partindo desse tipo de abordagem, pretendemos interpretar tanto os procedimentos de reescrita a que recorre Machado de Assis ao reeditar seus contos em livro quanto as variações derivadas de uma nova co-textualização, no âmbito da economia da coletânea de contos. Dito de outro modo, contamos por esse meio contribuir a devolver os contos "à sua textualidade esquecida e à sua historicidade" (idem, p. 26). 
Assim, pretendemos identificar e examinar os recursos de reescrita, cotejando as versões dos dezesseis contos: mudanças de títulos ou de pontuação, substituição ou supressão de palavras, reformulações de frases ou de parágrafos. Por outro lado, quando publicado de maneira avulsa na Gazeta, cada conto figura em meio a "reclames", "publicações a pedido", avisos, artigos, crônicas, capítulos de folhetim, editoriais, notícias breves; já no livro, os dezesseis contos vêm reunidos em um mesmo volume in-octavo, dispostos segundo uma ordem distinta da do jornal, sendo enquadrados por pelo menos três elementos peritextuais que estimulam e modulam a leitura de nova maneira: o título geral da coletânea, uma epígrafe tomada a Diderot, uma nota dirigida ao leitor que, antes de tudo, busca justificar as características do gênero literário escolhido. Em suma, ao ter acesso às diferentes versões do texto, o estudioso vê esboçar-se diante dos seus olhos um belo e vasto programa de leitura das dezesseis narrativas que Machado de Assis publicou nas colunas da Gazeta de Notícias e, mais tarde, nas páginas de Várias histórias.

\section{2}

Foi esse programa que delineamos, após termos concluído a tradução em francês, a introdução e as notas críticas para a edição bilingue do livro (ASSIS, 2015). A fim de concretizá-lo, porém, era necessário antes de tudo coletar os textos na versão publicada em jornal, tarefa que esperávamos realizar sem dificuldades, por pelo menos duas razões. Por um lado, no acervo da Biblioteca Digital da Fundação Biblioteca Nacional (BDFBN) encontra-se uma extensa coleção da Gazeta de Notícias; por outro, diversas obras, há décadas, vêm indicando as datas de publicação desses contos no jornal, a começar pela indispensável bibliografia de José Galante de Sousa (1955), passando por pelo menos quatro edições da coletânea de Machado de Assis (1975, 2004, 2008, 2007-2009). Conforme veremos, o trabalho de Galante de Sousa constitui um marco para os demais, que às vezes aliás são induzidos por ele em erro de datação.

Por meio de uma simples consulta do acervo da BDFBN, pudemos verificar a pertinência das datações indicadas por Galante de Sousa - e que foram unanimemente mantidas pelas demais fontes - para apenas onze dos dezesseis contos. São os textos que figuram no Quadro 1, alinhados por ordem de publicação no jornal: 


\begin{tabular}{|l|l|}
\hline Data & Título do conto \\
\hline 13 de julho de 1884 & "O enfermeiro" (publicado sob o título "Cousas íntimas") \\
\hline 8 de setembro de 1884 & "Conto de escola" \\
\hline 12 de outubro de 1884 & "Dona Paula" \\
\hline 28 de novembro de 1884 & "A cartomante" \\
\hline 1 de março de 1885 & $\begin{array}{l}\text { "Um apólogo" (publicado sob o título "A agulha e a } \\
\text { linha") }\end{array}$ \\
\hline 1 de março de 1885 & "Adão e Eva" \\
\hline 1 de agosto de 1885 & "A causa secreta" \\
\hline 5 de novembro de 1885 & "Uns braços" \\
\hline 22 de novembro de 1885 & "O cônego ou metafísica do estilo" \\
\hline 29 de junho de 1888 & "Um homem célebre" \\
\hline 18 de outubro de 1891 & "Mariana" \\
\hline
\end{tabular}

Foi possível localizar sem dificuldades, na BDFBN, o jornal correspondendo a cada uma dessas datas. Esses contos foram publicados na sétima e na oitava colunas da primeira página da data indicada, estendendo-se até a segunda página, em que ocupam uma parte da primeira coluna e, por vezes, também uma parte da segunda. Os contos "Um apólogo" e "Adão e Eva" foram publicados juntos, formando um tríptico que se chama "Três apólogos", que compreende relatos que Machado de Assis publicaria separadamente em livro: "Um apólogo" - com o título "A agulha e a linha" - "Adão e Eva" e "Os dicionários", retomado na coletânea Páginas recolhidas (1899), sob o título "O dicionário". Em suma, para esses onze contos, o trabalho de análise do "texto em variação" pode começar, já que dispomos da data e do texto do jornal...

No entanto, a localização das outras cinco histórias foi menos simples. Deparamo-nos com três tipos de percalços: a disparidade entre as datas indicadas por diferentes fontes secundárias; a inexatidão das datações transmitidas por todas as fontes; enfim, a inacessibilidade do texto, por causa de lacunas nos acervos consultados.

Nada que seja tão eficaz para contornar os dois primeiros tipos de dificuldades quanto... verificar a datação junto à fonte primária. Mal comparando, em relação à datação desses contos, seguimos de certo modo o conselho do narrador machadiano, no que tange à "opinião pânica e falsa" das "pessoas que vão ao Corcovado": partimos do princípio de que "Nem Corcovados, nem Himalaias, valem muita cousa ao pé da [nossa] cabeça, que os mede". 
Assim sendo, confrontamos nós mesmos as datas indicadas nos livros com os exemplares dos jornais a que se referiam.

No caso de "A desejada das gentes", o erro de datação aparece já em Galante de Sousa, que menciona o $6^{\circ}$ Suplemento Literário do dia 15 de julho de 1886, quando se trata do dia 15 de agosto de 1886. O engano foi reproduzido desde então pelas demais fontes, que não tiveram a iniciativa de verificar se o conto tinha realmente sido publicado naquela data. $\mathrm{O}$ equívoco é às vezes acompanhado de uma imprecisão, já que certas fontes (2004, 2007-2009, 2008) não mencionam a publicação no suplemento literário. Ao consultarmos o acervo da BDFBN, pudemos verificar que o conto "A desejada das gentes" foi publicado no suplemento literário de 15 de agosto de 1886, cuja primeira página reproduzimos: No caso d'“O diplomático", uma data incorreta também foi indicada por Galante de Sousa - 29 de outubro de 1886 -, mas corrigida em seguida para 29 de outubro de 1884 (1975), retomada novamente (2007-2009) e por fim corrigida uma segunda vez (2008). Ao consultarmos o acervo da BDFBN, pudemos confirmar que "O diplomático" foi de fato publicado nas páginas 1 e 2 da Gazeta de Notícias do dia 29 de outubro de 1884 (Figura 2): 


\section{* 6 Supplemento Litterario da "Gazeta de Noticias:}

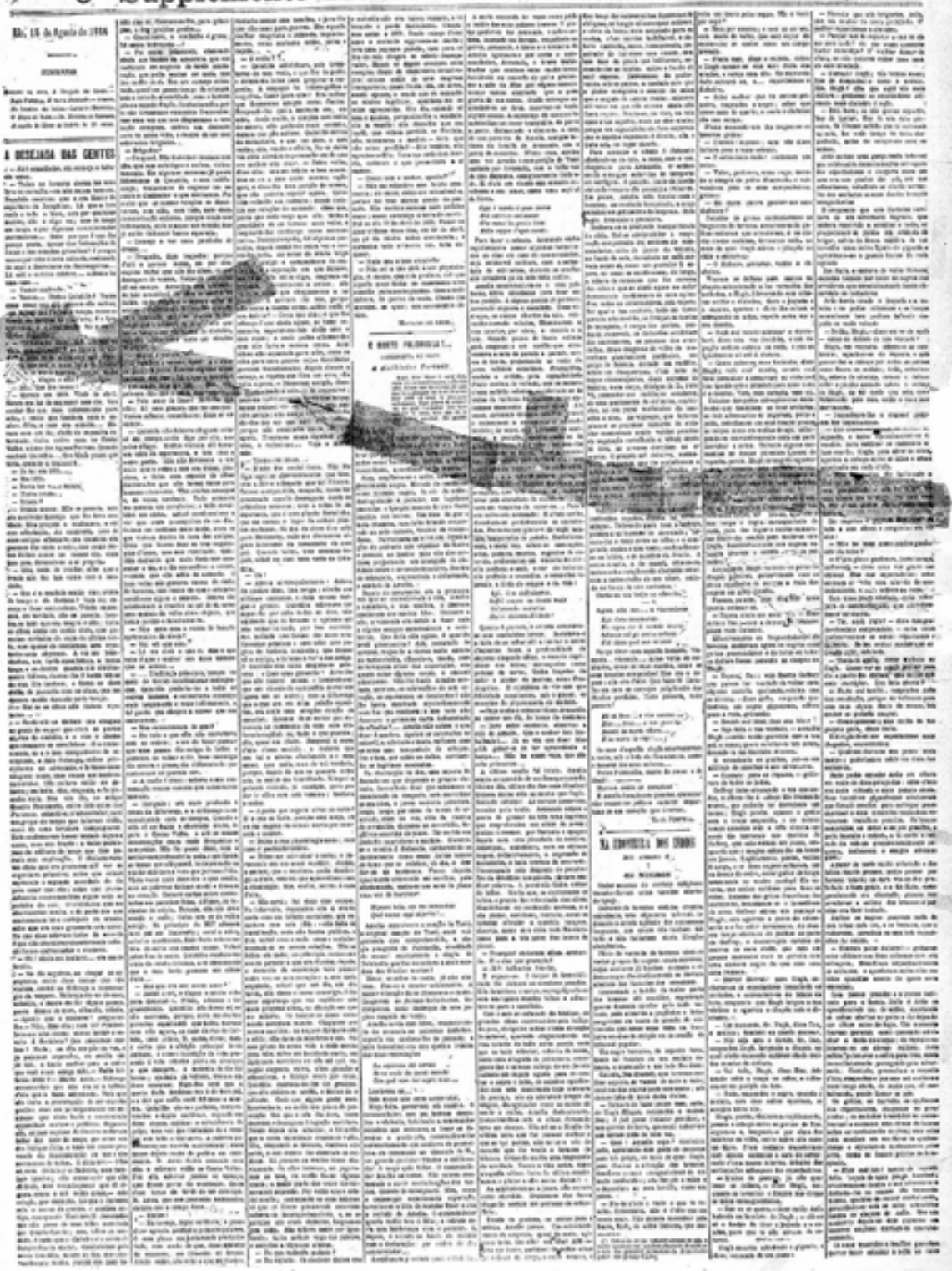

Figura 1: $6^{\circ}$ Suplemento Literário, Gazeta de Notícias 15 de agosto de 1866. 
No caso d'“O diplomático", uma data incorreta também foi indicada por Galante de Sousa - 29 de outubro de 1886 -, mas corrigida em seguida para 29 de outubro de 1884 (1975), retomada novamente (2007-2009) e por fim corrigida uma segunda vez (2008). Ao consultarmos o acervo da BDFBN, pudemos confirmar que "O diplomático" foi de fato publicado nas páginas 1 e 2 da Gazeta de Notícias do dia 29 de outubro de 1884:

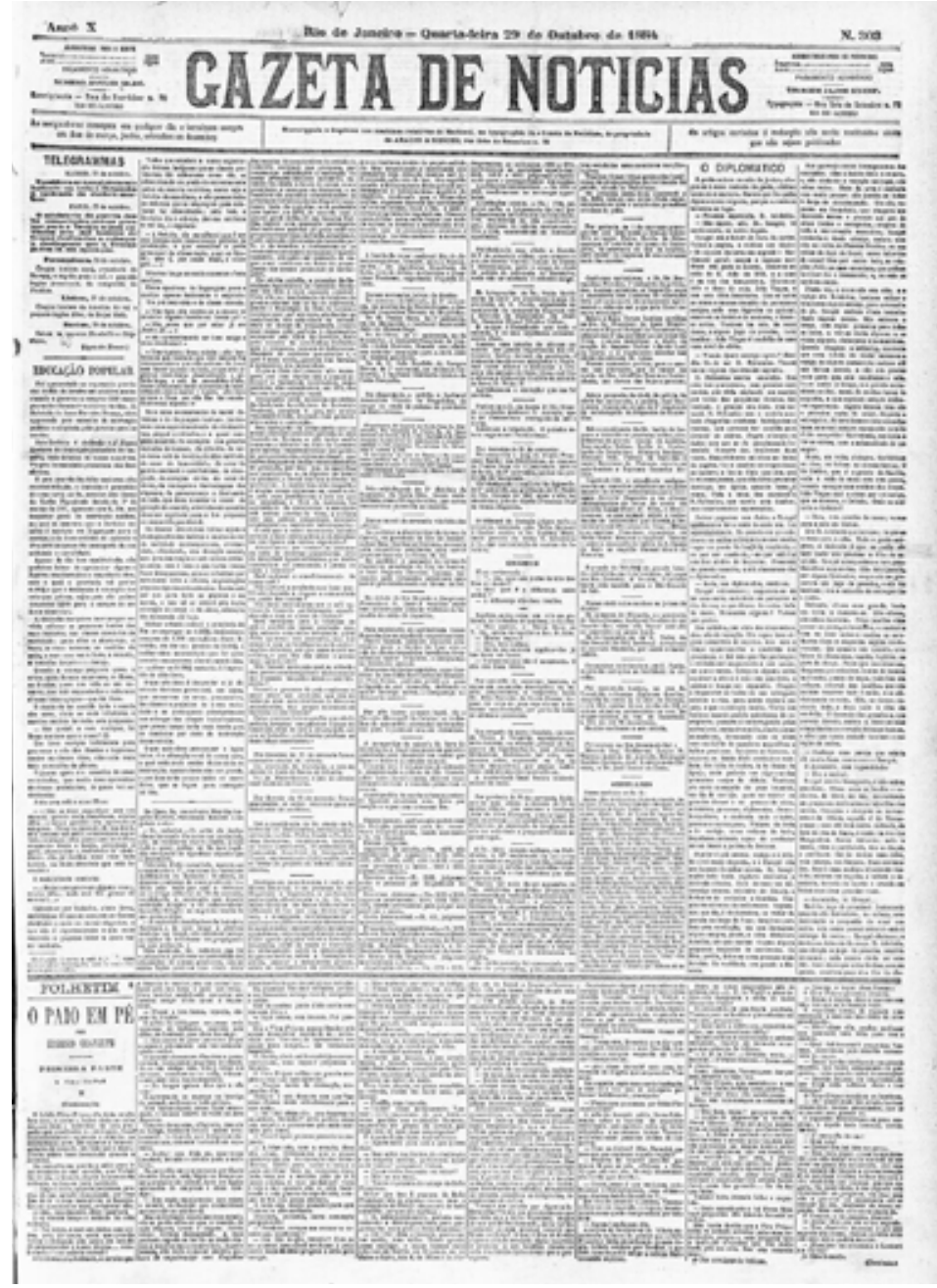

Figura 2: $6^{\circ}$ Gazeta de Notícias 15 de agosto de 1866. 
Finalmente, sobrevieram dificuldades decorrentes das lacunas do acervo da BDBFN. Números ausentes ou incompletos do jornal, que nos impossibilitam o acesso ao texto machadiano, apesar de se poder provar indiretamente a pertinência da datação postulada. Neste grupo, incluem-se "Entre santos", "Trio em lá menor" e "Viver!". Curiosa coincidência (simples fruto do acaso?...): todos os três contos inacessíveis foram publicados em 1886.

Segundo Galante de Sousa, o conto "Entre santos" foi publicado no suplemento literário de 1 de janeiro de 1886 . O exemplar do jornal não consta do acervo da BDFBN, mas o autor da Bibliografia, muito provavelmente, chegou a consultá-lo, já que a referência bibliográfica que indica vem acompanhada da seguinte observação: "No texto de Várias Histórias (1896), foram suprimidos os dizeres de Goethe, que se encontram, como epígrafe, na Gazeta de Notícias". Todas as outras fontes secundárias mantêm essa datação, com exceção de uma (2008), que a indica de maneira incompleta, sem mencionar a publicação do conto no suplemento literário.

A datação apresentada desde 1955 como sendo a de "Trio em lá menor" é 20 de janeiro de 1886, no suplemento literário. Nenhuma das fontes seguintes menciona o suplemento literário mas todas são fiéis à data indicada. À diferença porém d' "O diplomata", o acervo da Biblioteca Nacional, na época em que Galante de Sousa o consultou, já estava desfalcado do exemplar de 20 de janeiro de 1886. Apesar de tal lacuna, foi possível fixar a data sem consultar diretamente um exemplar do jornal, como explica o próprio autor da Bibliografia de Machado de Assis:

Não vimos o Suplemento Literário da Gazeta de Notícias, em que este conto foi publicado porque infelizmente é um dos números falhos na coleção do periódico, B. N. No mesmo Jornal de 19 de janeiro desse ano, encontra-se o anúncio do Suplemento, com a relação das peças que aí seriam publicadas. Que o conto, de fato, veio à luz no suplemento confirma-o a notícia que do mesmo se acha em A Semana, Rio, n 56, 23-1-1886.

Com efeito, A Semana destaca assim a qualidade do texto machadiano:

A Gazeta de Notícias publicou a 20 do corrente o seu segundo suplemento literário (...). Destacaremos o belo conto de Machado de Assis - Trio em lá menor - belo, original e entristecedor, como todos os seus contos (23 de janeiro de 1886, p. 27-28).

$\mathrm{O}$ autor da valiosa Bibliografia também recorreu a uma estratégia indireta de datação, no que diz respeito a "Viver!": 
Não vimos o suplemento literário da Gazeta de Notícias, em que apareceu este conto, porque é falha nesse $\mathrm{n}^{\circ}$ a coleção da B. N. Indicamo-lo, entretanto, baseado no anúncio que se encontra, no mesmo jornal (27-2-1886), com a descrição do conteúdo do suplemento, prometendo-o para o dia seguinte, e na confirmação de que realmente aí foi publicada a peça, pela notícia que da mesma se acha em A Semana, Rio, n 62, 6-3-1886

Como se pode constatar, A Semana apresenta o conto nos seguintes termos, bastante elogiosos:

A Gazeta de Notícias publicou no dia 28 do passado o seu $3^{\circ}$ suplemento literário. Não é inferior aos primeiros. Traz duas produções notáveis: uma em prosa Viver!, uma soberba alegoria da vida dialogada entre Ahasverus e Prometeu, original, primorosa e profunda como quanto sai da pena de ouro de Machado de Assis (...) (6 de março de 1886, p. 28).

Com o intuito de preencher essa lacuna, consultamos os acervos de sete outras instituições: Fundação Casa de Rui Barbosa (FCRB), Academia Brasileira de Letras (ABL), Real Gabinete Português de Leitura (RGPL), Biblioteca Brasiliana Guita e José Mindlin, Museu Republicano da Universidade de São Paulo, Fundação Joaquim Nabuco (Fundaj), Arquivo Público Estadual Jordão Emerenciano (APEJE) . Em vão: nenhum desses organismos dispõe dos números procurados.

Para resumir, recapitulamos no Quadro 3 os erros ou imprecisões de datação encontrados em relação aos cinco contos, mencionando também as constatações que podemos fazer, após o trabalho de consulta dos diferentes acervos e fontes secundárias: 


\begin{tabular}{|c|c|c|c|c|c|c|}
\hline & \multicolumn{6}{|c|}{ Datações } \\
\hline Título do conto & 1955 & 1975 & 2004 & 2007-2009 & 2008 & Constatação atual \\
\hline "Entre santos" & $\begin{array}{l}1 \text { de janeiro de } 1886, \\
\text { Suplemento Literário }\end{array}$ & $\begin{array}{c}1 \text { de janeiro de } \\
\text { 1886, Suplemento } \\
\text { Literário }\end{array}$ & $\begin{array}{c}1 \text { de janeiro } \\
\text { de } 1886\end{array}$ & $\begin{array}{l}1 \text { de janeiro de } \\
1886, \\
\text { Suplemento } \\
\text { Literário }\end{array}$ & $\begin{array}{c}1 \text { de janeiro } \\
\text { de } 1886\end{array}$ & $\begin{array}{c}1 \text { de janeiro, Suplemento } \\
\text { Literário, ausente da } \\
\text { BDFBN e exemplar do jornal } \\
\text { ausente dos acervos } \\
\text { consultados. }\end{array}$ \\
\hline $\begin{array}{l}\text { "Trio em lá } \\
\text { menor" }\end{array}$ & $\begin{array}{c}20 \text { de janeiro de } 1886, \\
2^{\circ} \text { Suplemento } \\
\text { Literário. }\end{array}$ & $\begin{array}{l}20 \text { de janeiro de } \\
1886 \text { (apud } A \\
\text { Semana, Rio de } \\
\text { Janeiro, } 23 \text { de } \\
\text { janeiro de } 1886 \text { ) }\end{array}$ & $\begin{array}{c}20 \text { de janeiro } \\
\text { de } 1886\end{array}$ & $\begin{array}{c}20 \text { de janeiro de } \\
1886\end{array}$ & $\begin{array}{c}20 \text { de janeiro } \\
\text { de } 1886\end{array}$ & $\begin{array}{c}\text { Suplemento Literário ausente } \\
\text { da BDFBN e exemplar do } \\
\text { jornal ausente dos acervos } \\
\text { consultados. Confirmação } \\
\text { indireta de } 20 \text { de janeiro de } \\
\text { 1886, já que, como ressalta } \\
\text { Galante de Sousa, a } \\
\text { publicação foi comentada n' } A \\
\text { Semana, } 23 \text { de janeiro de } \\
\text { 1886, a que se tem acesso } \\
\text { pela BDFBN. }\end{array}$ \\
\hline "Viver!" & $\begin{array}{c}28 \text { de fevereiro de } \\
1886,3^{\circ} \text { Suplemento } \\
\text { Literário. }\end{array}$ & $\begin{array}{c}28 \text { de fevereiro } \\
\text { de } 1886, \\
\text { Suplemento } \\
\text { Literário (apud A } \\
\text { Semana, } 6 \text { de } \\
\text { março de } 1886 \text { ) }\end{array}$ & $\begin{array}{c}28 \mathrm{de} \\
\text { fevereiro de } \\
1886\end{array}$ & $\begin{array}{l}28 \text { de fevereiro } \\
\text { de } 1886,3^{\circ} \\
\text { Suplemento } \\
\text { Literário }\end{array}$ & $\begin{array}{c}28 \text { de } \\
\text { fevereiro de } \\
1886\end{array}$ & $\begin{array}{c}\text { Suplemento Literário ausente } \\
\text { da BDFBN e exemplar do } \\
\text { jornal ausente dos acervos } \\
\text { consultados. Confirmação } \\
\text { indireta de } 28 \text { de fevereiro de } \\
1886, \\
\text { já que, como assinala Galante } \\
\text { de Sousa, a publicação foi } \\
\text { anunciada pela Gazeta de } \\
\text { Notícias na véspera da } \\
\text { publicação e confirmada por } \\
\text { A Semana, do dia } 6 \text { de março } \\
\text { de } 1886 .\end{array}$ \\
\hline $\begin{array}{c}\text { "A desejada das } \\
\text { gentes" }\end{array}$ & $\begin{array}{c}15 \text { de julho de } 1886,6^{\circ} \\
\text { Suplemento Literário }\end{array}$ & $\begin{array}{l}15 \text { de julho de } \\
1886, \\
\text { Suplemento } \\
\text { Literário }\end{array}$ & $\begin{array}{l}15 \text { de julho } \\
\text { de } 1886\end{array}$ & $\begin{array}{c}15 \text { de julho de } \\
1886\end{array}$ & $\begin{array}{c}15 \text { de julho } \\
\text { de } 1886\end{array}$ & $\begin{array}{l}\text { Retificação da data: } 15 \text { de } \\
\text { agosto de } 1886, \\
6^{\circ} \text { Suplemento Literário (em } \\
\text { vez de } 15 \text { de julho). }\end{array}$ \\
\hline "O diplomático" & 29 de outubro de 1886 & $\begin{array}{c}29 \text { de outubro de } \\
1884\end{array}$ & $\begin{array}{c}29 \text { de } \\
\text { outubro de } \\
1884\end{array}$ & $\begin{array}{c}29 \text { de outubro de } \\
1886\end{array}$ & $\begin{array}{c}29 \text { de } \\
\text { outubro de } \\
1884\end{array}$ & $\begin{array}{c}\text { Retificação da datação } \\
\text { indicada inicialmente: } \\
29 \text { de outubro de } 1884 \text { (em } \\
\text { vez de } 1886 \text { ). }\end{array}$ \\
\hline
\end{tabular}

Quadro 3: Datação de cinco contos, com retificações e complementos. 
Graças à confrontação entre as fontes secundárias mencionadas e os números da Gazeta de Notícias consultados, pudemos verificar a pertinência da data indicada para onze dos dezesseis contos: "A cartomante", "Uns braços", "Um homem célebre", "A causa secreta", "Adão e Eva", "O enfermeiro", "Mariana", "Conto de escola", "Um apólogo", "Dona Paula", "O cônego ou metafísica do estilo"; também conseguimos retificar a datação d'“A desejada das gentes" e d'“O diplomático". O acesso a esses treze textos foi possível, através de uma consulta da BDFBN. Em relação aos três outros contos ("Entre santos", “Trio em lá menor", "Viver!"), pudemos confirmar indiretamente as datações dadas em 1955 mas ainda nos é impossível ter acesso ao texto publicado em jornal, uma inacessibilidade que é fruto das lacunas existentes nas coleções de periódicos recolhidas nos acervos ao nosso dipor. Ou, melhor dizendo - pois a modéstia e o otimismo são os mais fiéis conselheiros do pesquisador... - dado o estado atual de acesso a essas coleções, não conseguimos ainda consultar a versão para o jornal de dois desses contos. Constatação provisória, que tem vocação a se modificar.

Esperando a descoberta possível de novos documentos - o que nos permitirá proceder a uma análise dos dezesseis contos da coletânea enquanto "texto em variação" - podemos pelo menos fazer um balanço definitivo da datação propriamente dita dos dezesseis contos, que o Quadro 4 apresenta segundo a disposição em que se sucedem no livro: 


\begin{tabular}{|c|c|c|}
\hline $\begin{array}{l}\text { Posição } \\
\text { ocupada no livro }\end{array}$ & Título do conto & Data \\
\hline 1 & "A cartomante" & 28 de novembro de 1884 \\
\hline 2 & "Entre santos" & 1 de janeiro de 1886 \\
\hline 3 & "Uns braços" & 5 de novembro de 1885 \\
\hline 4 & "Um homem célebre" & 29 de junho de 1888 \\
\hline 5 & "A desejada das gentes" & 15 de agosto de 1886 \\
\hline 6 & "A causa secreta" & 1 de agosto de 1885 \\
\hline 7 & “Trio em lá menor" & 20 de janeiro de 1886 \\
\hline 8 & "Adão e Eva" & 1 de março de 1885 \\
\hline \multirow[t]{2}{*}{9} & "O enfermeiro" & \\
\hline & (publicado sob o título "Cousas íntimas") & 13 de julho de 1884 \\
\hline 10 & "O diplomático" & 29 de outubro de 1884 \\
\hline 11 & "Mariana" & 18 de outubro de 1891 \\
\hline 12 & "Conto de escola" & 8 de setembro de 1884 \\
\hline 13 & "Um apólogo" & \\
\hline 14 & $\begin{array}{l}\text { (publicado sob o título "A agulha e a linha") } \\
\text { "Dona Paula" }\end{array}$ & $\begin{array}{l}1 \text { de março de } 1885 \\
12 \text { de outubro de } 1884\end{array}$ \\
\hline 15 & "Viver!" & 28 de fevereiro de 1886 \\
\hline 16 & "O cônego ou metafísica do estilo" & 22 de novembro de 1885 \\
\hline
\end{tabular}

Quadro 4: Datação definitiva dos dezesseis contos

"Não creias tu nisso, leitor amado. Nem Corcovados, nem Himalaias, valem muita cousa ao pé da tua cabeça, que os mede". A lição do narrador machadiano, aplicada ao ato de consultar acervos para proceder à datação dos contos, deve ser seguida com rigor, mas ela não constitui evidentemente um fim em si. Graças à precisão obtida no que diz respeito às datas de publicação dos contos na imprensa, podemos compreender melhor as circunstâncias iniciais de leitura do texto e também, ao localizarmos a primeira versão dos contos, proceder a uma leitura do "texto em variação". 


\section{ABSTRACT}

Additions and corrections of the attributed chronology of the short stories of Várias histórias, proposed by Galante de Sousa (1955), and since then transmitted without changes for several sources.

KEYWORDS: Machado de Assis; Gazeta de Notícias; Várias histórias; short story; chronology.

\section{REFERENNCIAS}

A Semana, Rio de Janeiro, 6 de março de 1886, vol. II, n 62. Disponível em: <http:// bndigital.bn.br/hemeroteca-digital/> . Acesso em: 24 de maio de 2015.

A Semana, Rio de Janeiro, 23 de janeiro de 1886, vol. II, $\mathrm{n}^{\circ}$ 56. Disponível em: $<$ http://bndigital.bn.br/hemeroteca-digital/>. Acesso em: 24 de maio de 2015.

ASSIS, Joaquim Maria Machado de, Várias histórias / Histoires diverses, edição bilingue, introdução, tradução e notas Saulo Neiva. Paris: Classiques Garnier, col. "Littératures du Monde", 2015.

ASSIS, Joaquim Maria Machado de, Várias histórias, edição e introdução Hélio de Seixas Guimarães. São Paulo: Martins Fontes, 2004.

ASSIS, Joaquim Maria Machado de, Várias histórias, Machado de Assis.net, coordenação Marta de Senna. Rio de Janeiro: Faperj / CNPq / Fundação Casa de Rui Barbosa, 2007-2009. Disponível em: <http://www.machadodeassis.net/hiperTx_romances/ obras/variashistorias.htm>. Acesso em: 23 de maio de 2015.

ASSIS, Joaquim Maria Machado de, Várias histórias, Rio de Janeiro: Laemmert \& C., 1896.

ASSIS, Joaquim Maria Machado de, Várias histórias, Rio de Janeiro: Garnier, 1903.

ASSIS, Joaquim Maria Machado de, Várias histórias, Rio de Janeiro: Garnier, 1904.

ASSIS, Joaquim Maria Machado de, Várias histórias, texto estabelecido pela comissão Machado de Assis, introdução José Guilherme Merquior. Rio de Janeiro / Brasília: Civilização Brasileira / INL, 1975.

ASSIS, Joaquim Maria Machado de, Várias histórias. Obra completa em quatro volumes, vol. II, organização Aluizio Leite, Ana Lima Cecilio, Heloisa Jahn. Rio de Janeiro: Nova Aguilar, 2008.

Gazeta de Notícias. Rio de Janeiro, 1884-1895. Disponível em: <http://bndigital. bn.br/hemeroteca-digital/>. Acesso em: 24 de janeiro de 2015. 
HEIDMANN, Ute e ADAM, Jean-Michel, Textualité et intertextualité des contes. Perrault, Apulée, La Fontaine, Lhéritier..., Paris: Classiques Garnier, col. "Lire le XVIIe Siècle”, 2010.

SOUSA, José Galante de, Bibliografia de Machado de Assis. Prefácio Augusto Meyer. Rio de Janeiro: Instituto Nacional do Livro / Ministério da Educação e Cultura, 1955.

Recebido em: 27 de maio de 2015

Aceito em: 05 de setembro de 2015 